\title{
Effects of Caustic Extraction on Properties of Viscose Grade Dissolving Pulp
}

\author{
Cindy Friebel ${ }^{1}$, Robert H. Bischof ${ }^{2}$, Gabriele Schild ${ }^{2}$, Karin Fackler ${ }^{2}$ and Ireen Gebauer $1,3, * \mathbb{B}$ \\ 1 Kompetenzzentrum Holz GmbH, Altenberger Straße 69, 4040 Linz, Austria; CindyFriebel@web.de \\ 2 Lenzing AG, Werkstraße 1, 4860 Lenzing, Austria; r.bischof@lenzing.com (R.H.B.); \\ g.schild@lenzing.com (G.S.); k.fackler@lenzing.com (K.F.) \\ 3 Fraunhofer Center for Chemical-Biotechnological Processes CBP, Am Haupttor, Building 1251, \\ 06237 Leuna, Germany \\ * Correspondence: ireen.gebauer@igb.fraunhofer.de
}

Received: 31 January 2019; Accepted: 20 February 2019; Published: 27 February 2019

\begin{abstract}
Viscose, a cellulose-based commodity fibre, is produced by pulping and bleaching of wood, yielding a high quality "dissolving pulp" which is then spun. During pulping and bleaching, effective hemicellulose extraction is required to allow fibre production. We present a design of experiments (DoE) approach to optimise caustic extraction in a total chlorine free (TCF) bleaching sequence (O-CE-Z-P) of beech wood sulphite pulp. Temperature and sodium hydroxide concentration were varied to identify highest xylan extraction yield, and a maximum xylan removal of $83 \%$ was achieved at $20{ }^{\circ} \mathrm{C}$ and $120 \mathrm{~g} / \mathrm{L} \mathrm{NaOH}$. Additionally, caustic extraction conditions were derived from the DoE model that led to pulps with high yield, high alpha cellulose content or uniform cellulose molecular weight distribution. Pulps from verification experiments exhibited good reactivity in viscose application tests. Hence, the presented O-CE-Z-P bleaching sequence can be considered as suitable for integrated viscose fibre production. We assume that the presented caustic extraction model will be useful for pulp and biorefinery researchers who work on caustic biorefinery processes involving hardwood feedstocks.
\end{abstract}

Keywords: dissolving pulp; viscose; caustic extraction; cellulosic fibres; textile fibres; pulp; wood

\section{Introduction}

Every year 100 million tons of fibres are produced globally to make textiles and technical products that serve human well-being. Less than half of these fibres are currently made from renewable resources such as cotton or wood [1]. From an environmental viewpoint, wood as raw material for cellulose fibre production is beneficial in terms of reduced irrigation water requirements and ecotoxicity, as compared to cotton [1]. The production of viscose fibres from wood in an integrated viscose fibre plant (i.e., combined dissolving pulp and viscose production) also produces fewer greenhouse gas emissions than petroleum-based and even bio-based polyethylene terephthalate fibre production [2].

To make viscose fibres, wood chips are initially converted to "brown-stock" pulp using either the kraft or the sulphite process that remove a high amount of non-cellulosic wood constituents such as hemicellulose and lignin. Subsequently, the pulp is further purified by a suitable sequence of bleaching stages to the dissolving pulp quality required by the respective fibre process [3,4]. Dissolving pulp is a type of pulp having a high cellulose content $(>90 \%)$, high purity, brightness, cellulose reactivity, and a uniform molecular weight distribution [3].

Bleaching sequences usually have at least one stage that is aimed at hemicellulose removal, because hemicellulose is process-disturbing in the viscose process [5]. This is particularly true for low molecular weight xylan, while high molecular weight xylan might be fibre forming, depending on its 
morphological distribution in the pulp [6]. Typically, hemicellulose reducing bleaching stages are either acidic or alkaline treatments, the latter classified as cold caustic extractions (CCE) at temperatures of 25-45 ${ }^{\circ} \mathrm{C}$ and hot caustic extraction (HCE) at 70-120 ${ }^{\circ} \mathrm{C}$ [7]. At higher temperatures, the treatments become rather unspecific and lead to side reactions including acidic or alkaline cellulose degradation [8] and hence the pulp yield of CCE is systematically higher than the pulp yield of HCE [9]. Caustic extraction of sulphite pulp is already applied in total chlorine free (TCF) bleaching sequences and with the goal to improve metal removal $[10,11]$, whereas especially HCE of kraft pulp is not reasonable as the pulp was already treated with hot alkali during pulping. Enzymatic removal of residual hemicellulose by xylanases and combinations of caustic extraction and xylanase treatments have also been reported as a more specific means to purify pulp but are known to have a limited effect on dissolving sulphite pulps, with xylan removals being usually lower than 50\% [12-15].

Many reports exist on the effects of caustic extraction on kraft pulp, but papers on caustic extraction of sulphite pulp are rare as well as on its application in a TCF bleaching sequence. Herein, we report on the optimisation of caustic extraction of sulphite pulp, the full analysis of the dissolving pulp after the complete TCF bleaching, and on the application of the obtained hemicellulose poor pulp in viscose fibre production. To the best of our knowledge, this is the first time the TCF bleaching of sulphite pulp including a caustic extraction was studied with respect to the viscose process.

\section{Materials and Methods}

\subsection{Alkaline Extraction}

Never-dried beech sulphite pulp, which was delignified with oxygen $(\mathrm{O})$, was supplied by Lenzing AG (Austria). Wet pulp equivalent to $80 \mathrm{~g}$ oven dry (od) pulp was put into polyethylene flasks (DoE-screening) or a lab high-shear mixer (validation experiments) and heated to the desired reaction temperature. Then, the preheated $\mathrm{NaOH}$ solution was added, the suspension with a consistency of $10 \%$ was well mixed and reacted at the corresponding temperature. After $30 \mathrm{~min}$, the pulp was filtered through a glass frit and the filtrate weighed and subjected to density, and dissolved organic carbon (DOC) content analysis.

The pulp was washed five times for 2 min with a $\mathrm{NaOH}$ solution $(20 \mathrm{~g} / \mathrm{L}, 80 \mathrm{~g})$ and filtered. Again, the filtrate was weighed and analysed. During all alkaline filtrations, as little air as possible was sucked through the pulp to prevent oxidation of the cellulosic material. Then, the pulp was washed ten times with deionized water ( $80 \mathrm{~g}$ each), the fibres separated by mixing in water for $10 \mathrm{~min}$ at a consistency of $3 \%$, filtrated, and washed five times with water (160 g) to ensure a pulp pH below 8.5. The combined filtrates were weighed and analysed.

The extraction yield was calculated based on the amount of starting material minus the sum of DOC found in all extraction solutions and washing filtrates. The DOC content of the lyes and washing filtrates was determined according to ÖNORM EN 1484 [16].

\subsection{Bleaching}

The extracted pulps were subjected to ozone $(Z)$ bleaching in a medium consistency mixer $(10 \%$ consistency, $45^{\circ} \mathrm{C}, \mathrm{pH} 2.5,5$ bar $\mathrm{O}_{3}$ ) and subsequently to peroxide (P) bleaching in polyethylene flasks ( $10 \%$ consistency, $70^{\circ} \mathrm{C}, 3 \mathrm{~g} \mathrm{NaOH}$ and $3 \mathrm{~g} \mathrm{H} \mathrm{H}_{2}$ per $\mathrm{kg}$ od pulp).

\subsection{Pulp Characterisation}

The kappa number of the pulp was analysed according to Tappi T236cm-85 (typical relative standard deviation (rsd) of the analysis is 5\%), intrinsic viscosity according to SCAN-CM 15:99 (rsd $1 \%$ ), brightness according to ISO 2470-1 (rsd 0.2\%), and alkali resistance R10 and R18 (the amount of pulp that is insoluble in $10 \%$ and $18 \% \mathrm{NaOH}$ solution, respectively) according to DIN 54355 (rsd $0.2 \%$ ) [17-20]. Fourier-transform Raman spectroscopy was used to determine the degree of crystallinity as well as the cellulose II content of the pulp samples (rsd 5\%, respectively) [21]. To determine 
the carbohydrate content of pulps and filtrates, the samples were subjected to two-stage total hydrolysis with sulphuric acid and analysed by high-performance anion exchange chromatography with pulsed amperometric detection ( $\mathrm{rsd} 0.7 \%$ and $1.9 \%$ of glucan and xylan content, respectively) [22]. The molar mass distribution of the pulps was determined by size-exclusion chromatography (SEC) with multiangle light scattering and refractive index detection in a $\mathrm{LiCl} /$ dimethylacetamide solution [23]. The polydispersity index (PDI) of the pulps was calculated according to Equation (1), where $\mathrm{M}_{\mathrm{w}}$ is the weight average molecular weight and $\mathrm{M}_{n}$ is the number average molecular weight (rsd of PDI 9.7\%). The lower is the PDI-value, the more uniform is the molecular weight distribution of the pulp.

$$
P D I=\frac{M_{w}}{M_{n}}
$$

Moreover, the applicability of some pulp samples as viscose was tested. Thus, viscose was prepared in laboratory scale including steeping of the pulp in $\mathrm{NaOH}$ solution, pressing, shredding, ageing, preparation of xanthate by reaction with $\mathrm{CS}_{2}$, ripening and dissolving in $\mathrm{NaOH}$ [24]. The particle content and Treiber filterability of the viscose was analysed (rsd $4.1 \%$ of particle content, and rsd $2.5 \%$ of filter value) [25], a high-quality viscose is characterised by low particle content and high Treiber filtration value [26].

\subsection{Design of Experiments}

A design of experiment approach was chosen to keep the number of extraction experiments to a minimum and to create a model which reliably predicts experimental conditions giving pulps with desired features. The program Design Expert 10 was used for setting up a face centred central composite experimental design for alkaline extractions with $\mathrm{NaOH}$ concentrations ranging $40-120 \mathrm{~g} / \mathrm{L}$ and extraction temperatures of $20-80^{\circ} \mathrm{C}$. Duplicates were performed for the experiments at the corners and the centre point of the experimental design (squares in Figure 1).

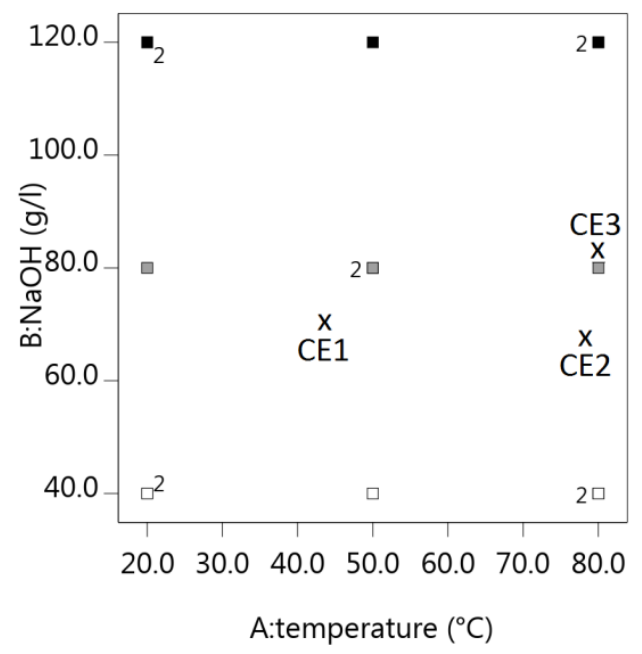

Figure 1. Applied experimental design of optimisation (squares) and validation experiments (crosses).

The 14 obtained pulps were analysed (Table A1) and a response surface model was calculated for each feature (Table A2). The experimental errors were determined from the replicates. Then, three more extractions (crosses in Figure 1) were carried out to verify the models. 


\section{Results and Discussion}

\subsection{DoE Models, Effects of Alkaline Extraction on Pulp}

With the help of DoE, 14 experiments were chosen and carried out to study the effect of $\mathrm{NaOH}$ concentration and temperature during caustic extraction on the kappa number, brightness, viscosity, alkali resistance R10 and R18, PDI, glucan and xylan content, cellulose crystallinity index, and cellulose II content of oxygen delignified sulphite pulp (see Table A1). The pulp yield of the extraction was also examined and statistical models were determined to describe the experimental data (Table A2).

All determined responses showed a complex correlation to temperature and $\mathrm{NaOH}$ concentration. More precisely, the xylan content (Figure 2) and pulp viscosity (Figure A1) decreased or increased, respectively, with elevated $\mathrm{NaOH}$ concentration but were least affected at intermediate temperatures.

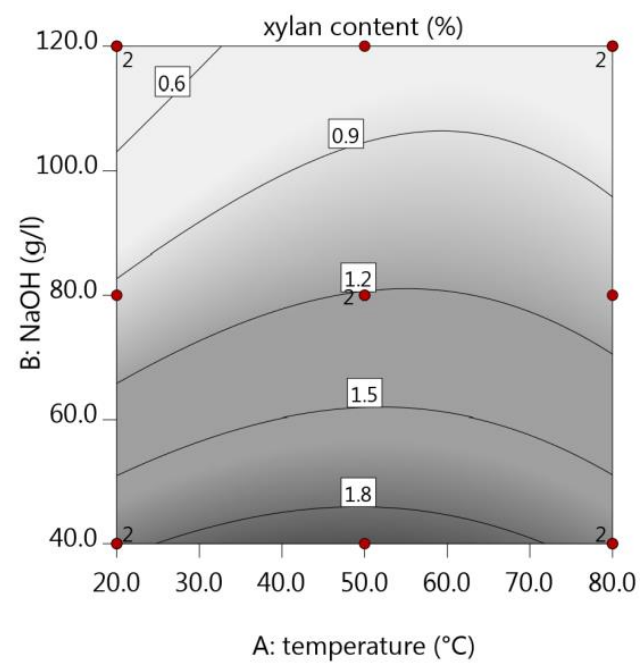

Figure 2. The xylan content of extracted sulphite pulp in correlation to temperature and $\mathrm{NaOH}$ concentration.

The xylan content of the pulp could be significantly reduced; a maximum reduction from $2.4 \%$ to $0.4 \%$ was achieved at $20^{\circ} \mathrm{C}$ and $120 \mathrm{~g} / \mathrm{L} \mathrm{NaOH}$, which corresponds to a reduction of $83 \%$. In contrast, only $17 \%$ of xylan was removed by caustic extraction at $50{ }^{\circ} \mathrm{C}$ and $40 \mathrm{~g} / \mathrm{L} \mathrm{NaOH}$. In general, more xylan was extracted at lower temperatures due to the removal mechanism: pulp easily swells at temperatures of $0-40{ }^{\circ} \mathrm{C}$ in alkaline solutions making short molecular chains accessible and allowing them to dissolve [27]. As depicted in Figure 3, the more hemicellulose was extracted, the higher was the $\mathrm{NaOH}$ concentration and more intensive was the swelling. Similar observations were made by Wayman and Sherk, who obtained chlorinated sulphite pulps with very high cellulose contents of $>99 \%$ by caustic extraction with $120-140 \mathrm{~g} / \mathrm{L} \mathrm{NaOH}$ at $15-20^{\circ} \mathrm{C}$ [28]. 


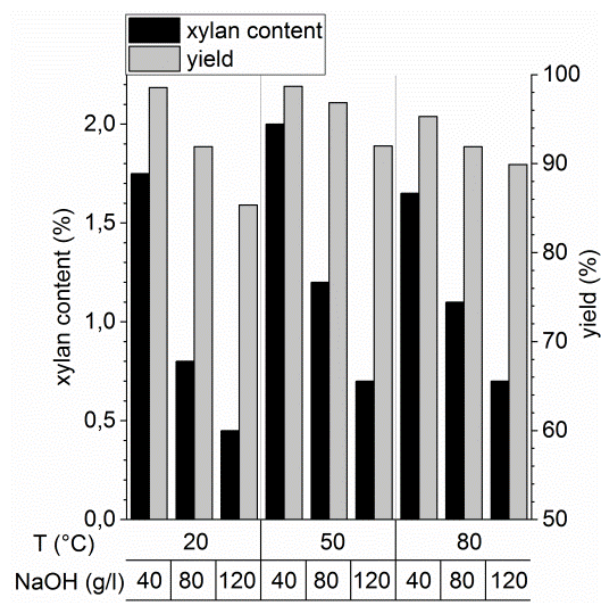

Figure 3. The residual xylan contents and pulp yields of caustic extraction experiments (averages of duplicates are shown).

The extraction of hemicellulose from the sulphite pulp was accompanied by cellulose removal, resulting in significant yield losses with lower achieved xylan content (see Figure 3). However, short chain cellulose is a minor component of pulp and therefore cold caustic extraction and accompanied swelling is highly selective to hemicellulose removal. It consequently caused an increase in the alkali resistance R18, a narrowing of the molecular weight distribution as well as PDI decrease, and consequently an increase of the average pulp viscosity (see Figure 4).
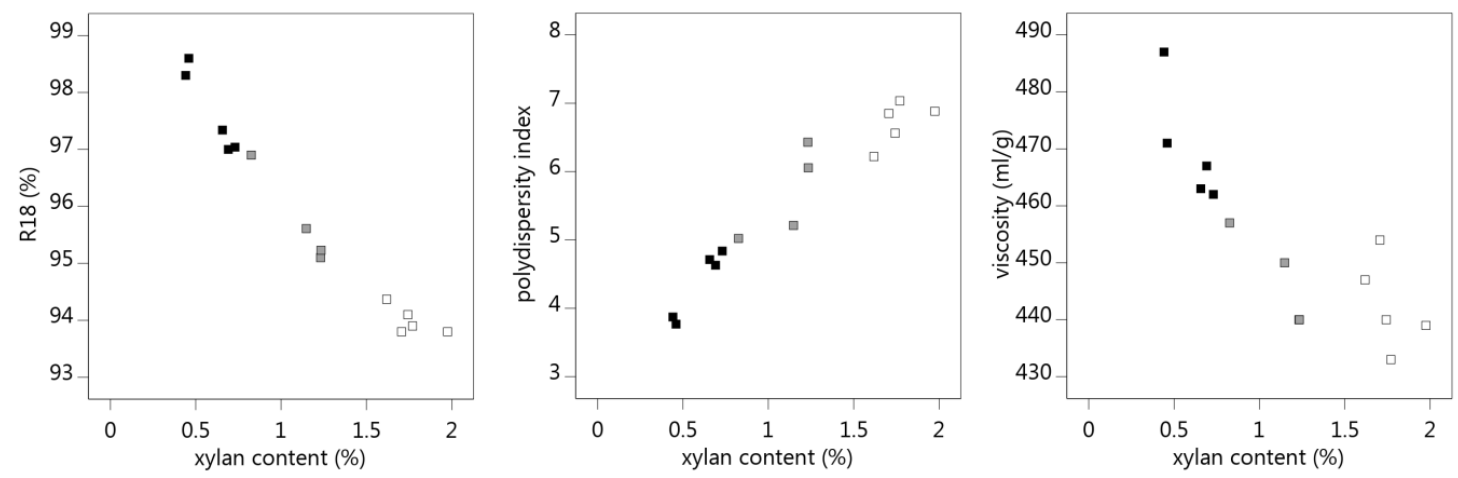

Figure 4. Observed correlations between pulp xylan content and R18 ( -0.983$)$, the polydispersity index (0.960), and pulp viscosity $(-0.846)$. The dot colour corresponds to the $\mathrm{NaOH}$ concentration of the respective experiment: white, $40 \mathrm{~g} / \mathrm{L}$; grey, $80 \mathrm{~g} / \mathrm{L}$; black, $120 \mathrm{~g} / \mathrm{L}$.

When the caustic extraction temperature increases at constant $\mathrm{NaOH}$ concentration, pulp swelling is reduced and xylan dissolution is hampered [29]. The main carbohydrate removal mechanism changes from the physical phenomenon to less effective chemical degradation reactions. Then, alkaline peeling gains importance, which degrades cellulose and hemicellulose in comparable rates making it a less selective carbohydrate removal mechanism. Therefore, in our study, comparatively more hemicellulose remained in the pulp at higher temperatures (see Figure 3). However, the pulp yield did not significantly decrease at $80^{\circ} \mathrm{C}$ due to peeling, as strong alkaline cellulose degradation including hydrolysis begins only at temperatures exceeding $140{ }^{\circ} \mathrm{C}$ [7].

Moreover, by also applying caustic extraction the pulp brightness was slightly improved, the effect being largest at high $\mathrm{NaOH}$ concentration and very low temperatures (Figure A2). In contrast, the kappa number was always lowered from 1.2 to 0.9 and was virtually independent of the extraction conditions (Table A1). Removal of chromophores from pulp by caustic extraction was not expected, because caustic extraction is not primarily applied for brightness improvement purposes and alkaline 
fibre swelling cannot significantly contribute to lignin removal [30], as well as sulphite pulping of hardwood followed by oxygen delignification is already a very effective lignin removal process. The remaining chromophores might comprise condensed wood extractives or minor amounts of lignin chemically bonded to hemicellulose. As caustic extraction does not degrade these compounds, our proposed explanation is that they might be removed by co-extraction with hemicellulose [7].

\subsection{Targeted Extraction}

The statistical models from the DoE experiments (Table A2) were used to determine caustic extraction conditions, which ideally satisfy the typical requirements of dissolving pulp producers: the pulp should be obtained in high yield, with low xylan content, high R18, and appropriate viscosity. Furthermore, a high pulp reactivity is desired, which is attributed to low crystallinity and low cellulose II content $[4,15]$. Clearly, not all of these objectives can be realised by a single caustic extraction. Therefore, different targets were defined for three single model validation experiments (see Table 1).

Table 1. Targets and conditions of validation experiments.

\begin{tabular}{cccc}
\hline & Experimental Goal & NaOH $(\mathrm{g} / \mathrm{L})$ & Temperature $\left({ }^{\circ} \mathbf{C}\right)$ \\
\hline CE1 & high yield, high R18 & 70 & 44 \\
CE2 & high temperature, high R18 & 66 & 78 \\
CE3 & high temperature, low PDI & 82 & 80 \\
\hline
\end{tabular}

The objective of the first extraction CE1 was to obtain a pulp in high yield as well as in high purity represented by high R18 and low xylan content. It has been reported before that sulphite pulps with very high cellulose contents of $98 \%$ can be obtained by applying caustic extractions at temperatures of $5-50{ }^{\circ} \mathrm{C}$ and $\mathrm{NaOH}$ concentrations of 20-140 g/L [28]. As described above, the caustic extraction selectivity is highest at low temperatures in terms of xylan removal while glucan is preserved. However, a high temperature process is more easily integrated into an existing bleaching sequence. Hence, lower yields were accepted for CE2 and CE3, while nevertheless a high R18 was aimed at in CE2. A low PDI was targeted by CE3, and therefore the response surface models provided us with extraction conditions preventing significant pulp degradation and securing the cellulose chain lengths.

Caustic extractions according to the validation experiments CE1, CE2, and CE3 were carried out. The predicted and actual properties of the three obtained pulps after caustic extraction are listed in Table 2. The experimental pulp properties agree with the predicted values within the standard deviation $\sigma$, proving that the DoE models were valid. However, the cellulose II content could only be predicted with unreasonably high $\sigma$ and the yield of experiment CE3 with $89.1 \%$ was significantly lower than predicted $(92.3 \%)$. This might be due to the fact that the extraction conditions of experiment CE3 were located on the outer borders of the DoE model (see Figure 1) giving rise to a higher uncertainty of prediction or that a different experimental setup was used for validation experiments. A lab high-shear mixer was used instead of polyethylene flasks for caustic extraction resulting in higher yield losses during handling. 
Table 2. Pulp properties of oxygen delignified pulp, pulp after alkaline extraction (predicted and actual), and further Z-P-bleached dissolving pulp.

\begin{tabular}{|c|c|c|c|c|c|c|c|c|c|c|c|}
\hline \multirow{2}{*}{$\begin{array}{l}\text { Bleaching } \\
\text { Sequence }\end{array}$} & \multirow[t]{2}{*}{ O } & \multicolumn{4}{|c|}{ O-CE } & \multicolumn{3}{|c|}{ O-CE } & \multicolumn{3}{|c|}{ O-CE-Z-P } \\
\hline & & CE1 & CE2 & CE3 & $\sigma$ & CE1 & CE2 & CE3 & CE1 & CE2 & CE3 \\
\hline parameter & & \multicolumn{4}{|c|}{ calculated } & \multicolumn{3}{|c|}{ observed } & \multicolumn{3}{|c|}{ observed } \\
\hline kappa number & 1.2 & 0.9 & 0.9 & 0.9 & 0.04 & 0.9 & 0.9 & 0.9 & 0.1 & 0.1 & 0.1 \\
\hline $\begin{array}{l}\text { brightness } \\
\text { (\%ISO) }\end{array}$ & 75.7 & 79.2 & 80.7 & 80.9 & 0.8 & 78.5 & 80.0 & 81.0 & 91.8 & 93.0 & 93.6 \\
\hline viscosity $(\mathrm{ml} / \mathrm{g})$ & 435 & 440 & 450 & 455 & 6 & 445 & 455 & 460 & 405 & 400 & 400 \\
\hline R10 $(\%)$ & 84.7 & 86.4 & 86.3 & 87.0 & 0.6 & 86.2 & 86.8 & 87.7 & 84.8 & 85.6 & 86.2 \\
\hline R18 (\%) & 92.7 & 95.0 & 95.0 & 95.6 & 0.3 & 94.8 & 94.9 & 95.8 & 94.7 & 94.8 & 95.8 \\
\hline PDI & 7.1 & 6.3 & 5.9 & 5.5 & 0.3 & 5.9 & 6.0 & 5.5 & 5.8 & 5.4 & 5.0 \\
\hline xylan $(\%)$ & 2.4 & 1.3 & 1.4 & 1.1 & 0.1 & 1.4 & 1.4 & 1.1 & 1.4 & 1.3 & 1.1 \\
\hline $\begin{array}{c}\text { crystallinity } \\
\text { index (\%) }\end{array}$ & 55 & 54 & 55 & 55 & 1 & 53 & 53 & 53 & 53 & 54 & 53 \\
\hline cellulose II (\%) & 4 & 8 & 6 & 6 & 8 & 13 & 12 & 12 & 12 & 12 & 13 \\
\hline yield DOC (\%) & 95.7 & 97.0 & 93.8 & 92.3 & 0.9 & 97.3 & 94.0 & 89.1 & 99.4 & 99.4 & 99.5 \\
\hline particles (ppm) & & & & & & & & & 7.1 & 4.4 & 4.4 \\
\hline $\begin{array}{l}\text { filtration value } \\
\qquad\left(\mathrm{g} / \mathrm{cm}^{2}\right)\end{array}$ & & & & & & & & & 390 & 400 & 421 \\
\hline
\end{tabular}

All three caustic extraction experiments had similar effects on the sulphite pulp (see Table 2). The pulp brightness was raised by $3-5 \%$ points and the xylan content was reduced by about $50 \%$. As expected, highest yield was achieved in experiment CE1 due to the lowest applied temperature. However, even under the harshest applied conditions of $82 \mathrm{~g} / \mathrm{L} \mathrm{NaOH}$ and $80^{\circ} \mathrm{C}$ in CE3, no significant peeling of the long-chain cellulose appeared. Since alkaline cellulose degradation begins at temperatures exceeding $140{ }^{\circ} \mathrm{C}$ [7], the distribution of high molar mass carbohydrates remained basically constant, as illustrated in Figure 5 for CE3. Only low molecular weight hemicellulose was extracted under the given conditions probably by the swelling and dissolution process. Consequently, the xylan content in the pulp declined to $1.1 \%$ and the alkali resistances R10 and R18 increased to $87.7 \%$ and $95.8 \%$, respectively (Table 2 ). Moreover, the average pulp viscosity increased while the PDI was reduced as the molecular weight distribution became narrower.

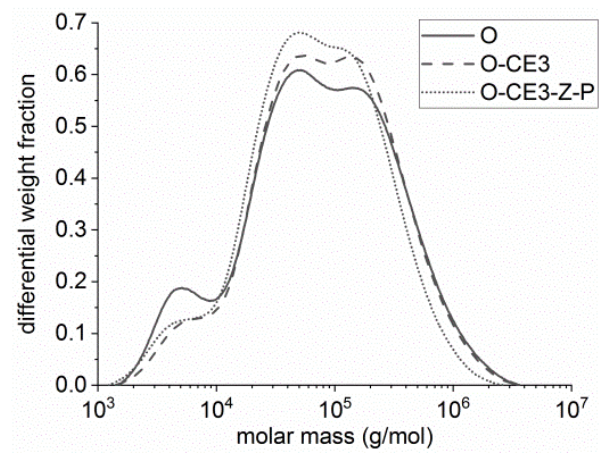

Figure 5. Distribution of pulp molecular weight.

\subsection{Bleaching and Viscose Testing}

After caustic extraction, the pulp was bleached with ozone and peroxide, i.e., a TCF bleaching sequence was applied. The superior quality of the extracted pulp comprised very low kappa number, very high brightness, high R18, and low PDI as well as very low residual xylan content. Overall pulp yields of $92.6 \%, 89.4 \%$ and $84.8 \%$ were achieved in the O-CE-Z-P bleaching sequence for CE1, CE2, and CE3, respectively. Even though a yield of $96.3 \%$ has been reported for a TCF bleaching of beech 
sulphite pulp, our results were still in an acceptable range, as the reported pulp was only treated with peroxide and the brightness was $88.5 \%$ ISO [31].

The molecular weight distribution of the pulp along the bleaching sequence is depicted in Figure 5. Caustic extraction clearly reduced the amount of short chain hemicellulose, as discussed above. The high molecular weight cellulose was not significantly shortened by caustic extraction. In contrast, ozone bleaching caused oxidation of the cellulosic hydroxyl groups and subsequent hydrolysis of internal glycosidic bonds led to a chain length reduction, which is observed in Figure 5 by a shift of the right-end curve to lower molecular mass [32].

Whenever native cellulose - the structure named cellulose I-is subjected to strong alkaline solutions, it undergoes mercerization. The hydrogen bonds between the carbohydrate chains are loosened, the cellulose swells and upon neutralisation it changes its structure to cellulose II, which is less reactive towards chemicals compared to cellulose I. Usually, the crystallinity of cellulose is decreased during mercerization (see Table 2), which in turn results in an increased reactivity. Hence, the effect of caustic extraction on the reactivity of pulp is complex and not easily predicted and, therefore, the actual viscose quality needs to be tested by the Treiber filterability and the particle content. The test results shown in Table 2 prove the bleached pulp gave a high-quality viscose, as the filtration values around $400 \mathrm{~g} / \mathrm{cm}^{2}$ were quite high and only a few particles were detected. Presumably, the variations in crystallinity and cellulose II of the pulp did not have a notable effect on the viscose process, because during steeping and ageing in the viscose process the alkali cellulose undergoes more intense mercerization exceeding the mercerization by caustic extraction. The obtained pulps were therefore highly suitable for industrial processing.

\subsection{Process Viability}

Dissolving pulp of very high quality can be produced from sulphite pulp by O-CE-Z-P bleaching. This process offers therefore high potential for the production not only of viscose but also of other value-added products requiring highly pure pulp, such as lyocell or cellulose filaments.

The applied O-CE-Z-P bleaching sequence is also energetically favourable and can be integrated into existing TCF bleaching sequences. A typical O-CE-Z-P temperature profile could be $100{ }^{\circ} \mathrm{C}, 80^{\circ} \mathrm{C}$, $50{ }^{\circ} \mathrm{C}$, and $70{ }^{\circ} \mathrm{C}$ and hence the temperature descends slowly through the treatment.

The demonstrated caustic extraction utilised lyes with a $\mathrm{NaOH}$ concentration of 70-80 g/L. Since alkali lyes of this composition are usually not available in sulphite or kraft pulp mills but are a crucial resource in viscose production, the application of the O-CE-Z-P bleaching sequence could be of particular interest in a pulp mill with integrated viscose production. As hemicellulosic degradation products accumulate in viscose lyes during the recycling in the viscose production and need to be removed, e.g., by nanofiltration [5] or other membrane separation processes [33], it would be economically advantageous to constantly direct part of the viscose lye to caustic extraction, consequently keep the carbohydrate concentration in the viscose production low and possibly save the installation of costly separation equipment. In addition, the lyes used in caustic extraction could even be redirected to the preceding oxygen bleaching stage and, consequently, large amounts of fresh lye could be saved or its utilisation could even be omitted from the bleaching sequence.

By applying a caustic extraction in the bleaching of pulp, hemicelluloses are removed from pulp at an earlier point in the process compared to usual residual hemicellulose degradation during viscose steeping and ageing. Moreover, the extracted hemicelluloses exhibit longer chain lengths compared to the low molecular weight hemicellulose obtained from the steeping lye. Because oligomeric sugar containing lyes are of special interest in a biorefinery context, where they are further processed, e.g., into xylooligosaccharides for prebiotic formulations [34,35], a co-product of higher market value can be separated by the described process.

The overall yield of the applied bleaching sequence was acceptable, but pulp producers strive for highest possible product amounts. However, applying the O-CE-Z-P bleached pulp in a viscose process certainly gives higher viscose yields and throughput, because carbohydrate losses due to 
hemicellulose removal would be significantly reduced during ageing and steeping, as hemicellulose had already been removed almost quantitatively. Additionally, the aging time could be reduced because the viscosity of the pulps was much lower. Hence, O-CE-Z-P bleached sulphite pulp can be considered as a promising resource for the viscose or lyocell process.

\section{Conclusions}

Dissolving pulp in outstanding purity was obtained from sulphite beech pulp by application of an O-CE-Z-P bleaching sequence. Up to $83 \%$ of xylan was removed from the pulp, and only minor yield losses arose from cellulose degradation. The major benefit of caustic extraction as described here is its high selectivity, as yield loss corresponds to xylan extraction while cellulose is preserved, whereas during hot caustic extraction significant cellulose losses occur [7]. Caustic extractions carried out at about $80^{\circ} \mathrm{C}$ with $60-80 \mathrm{~g} / \mathrm{L} \mathrm{NaOH}$ were economically feasible, because pulp was obtained in good yield and an energetically moderate temperature profile was applied throughout the bleaching sequence.

The dissolving pulp showed very good reactivity in viscose application tests, and its high purity makes it a promising candidate for further high-value products. Application of the described bleaching process in a pulp mill with integrated viscose production offers economic and environmental advantages for the whole process due to the complementary utilisation of viscose lyes and hemicellulose as a co-product.

Author Contributions: Investigation, C.F.; writing—draft preparation, I.G.; writing—editing R.B. and G.S.; visualisation, I.G.; and conceptualisation and supervision, K.F.

Funding: Financial support was provided by the Austrian government; the provinces of Lower Austria, Upper Austria, and Carinthia; and by Lenzing AG.

Acknowledgments: We express our gratitude to the Lenzing AG for their kind contributions.

Conflicts of Interest: The authors declare no conflict of interest.

\section{Appendix A}

Table A1. DoE layout and results.

\begin{tabular}{|c|c|c|c|c|c|c|c|c|c|c|c|c|c|c|}
\hline \multirow[b]{2}{*}{ 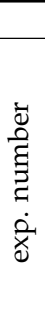 } & \multirow[b]{2}{*}{ 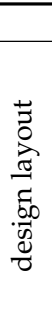 } & \multicolumn{2}{|c|}{ Variables } & \multicolumn{11}{|c|}{ Response } \\
\hline & & 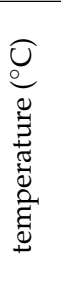 & 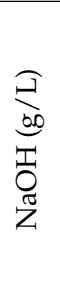 & 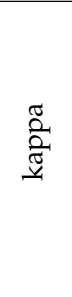 & 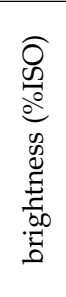 & 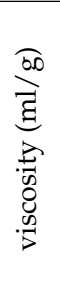 & $\begin{array}{l}\widehat{\varrho} \\
\stackrel{0}{\circ} \\
\stackrel{a}{a}\end{array}$ & $\begin{array}{l}\widehat{\varrho} \\
\stackrel{\infty}{0} \\
\vec{\simeq}\end{array}$ & $\overline{\mathrm{Q}}$ & $\begin{array}{l}\widehat{\partial} \\
\stackrel{\Xi}{0} \\
\frac{\tilde{U}}{\partial} \\
0.0\end{array}$ & 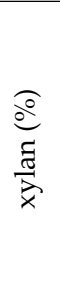 & 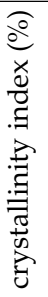 & 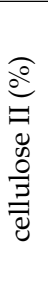 & $\frac{\widehat{o}}{\frac{0}{2}}$ \\
\hline 4 & - & 20 & 40 & 0.84 & 78.3 & 433 & 85.4 & 93.9 & 7.0 & 96.5 & 1.8 & 54 & 8 & 98.6 \\
\hline 13 & - & 20 & 40 & 0.99 & 79.2 & 440 & 85.8 & 94.1 & 6.6 & 97.8 & 1.7 & 54 & 8 & 98.5 \\
\hline 14 & $0-$ & 50 & 40 & 0.95 & 79.9 & 439 & 85.7 & 93.8 & 6.9 & 95.5 & 2.0 & 54 & 9 & 98.7 \\
\hline 1 & +- & 80 & 40 & 0.90 & 80.0 & 454 & 86.0 & 93.8 & 6.9 & 96.9 & 1.7 & 54 & 7 & 95.8 \\
\hline 11 & +- & 80 & 40 & 0.91 & 80.8 & 447 & 86.5 & 94.4 & 6.2 & 96.7 & 1.6 & 54 & 10 & 94.8 \\
\hline 12 & -0 & 20 & 80 & 0.90 & 78.8 & 457 & 90.2 & 96.9 & 5.0 & 96.8 & 0.8 & 52 & 14 & 91.9 \\
\hline 5 & 00 & 50 & 80 & 0.85 & 79.7 & 440 & 86.3 & 95.1 & 6.4 & 98.1 & 1.2 & 55 & 6 & 96.9 \\
\hline 7 & 00 & 50 & 80 & 0.94 & 80.1 & 440 & 86.6 & 95.2 & 6.1 & 96.8 & 1.2 & 54 & 8 & 96.8 \\
\hline 9 & +0 & 80 & 80 & 0.90 & 80.7 & 450 & 87.4 & 95.6 & 5.2 & 96.9 & 1.1 & 53 & 9 & 91.9 \\
\hline 3 & -+ & 20 & 120 & 0.85 & 76.5 & 487 & 96.5 & 98.3 & 3.9 & 99.0 & 0.4 & 46 & 75 & 85.5 \\
\hline 6 & -+ & 20 & 120 & 0.91 & 75.2 & 471 & 96.9 & 98.6 & 3.8 & 96.7 & 0.5 & 45 & 79 & 85.2 \\
\hline 10 & $0+$ & 50 & 120 & 0.93 & 80.1 & 463 & 92.0 & 97.3 & 4.7 & 98.5 & 0.7 & 50 & 28 & 92.0 \\
\hline 2 & ++ & 80 & 120 & 0.89 & 80.5 & 467 & 90.5 & 97.0 & 4.6 & 96.8 & 0.7 & 53 & 14 & 90.9 \\
\hline 8 & ++ & 80 & 120 & 0.89 & 81.1 & 462 & 89.9 & 97.0 & 4.8 & 96.5 & 0.7 & 52 & 16 & 88.9 \\
\hline
\end{tabular}


Table A2. Coefficients of response regression models with the equation: response $=X+A+B+A \cdot B+$ $\mathrm{A}^{2}+\mathrm{B}^{2}$. $\mathrm{A}$ is temperature and $\mathrm{B}$ is $\mathrm{NaOH}$ concentration.

\begin{tabular}{c|cccccccc}
\hline Response & $\mathbf{X}$ & $\mathbf{A}$ & $\mathbf{B}$ & $\mathbf{A} \cdot \mathbf{B}$ & $\mathbf{A}^{\mathbf{2}}$ & $\mathbf{B}^{\mathbf{2}}$ & $\mathbf{\sigma}$ & $\mathbf{R}^{\mathbf{2}}$ \\
\hline brightness & +80.4069 & -0.0025 & -0.0448 & +0.0007 & & & 0.8031 & 0.8240 \\
viscosity & +445.1235 & -0.5816 & -0.0375 & -0.0059 & +0.0103 & +0.0042 & 5.52 & 0.9191 \\
R10 & +85.9130 & -0.0869 & +0.0186 & +0.0015 & +0.0016 & +0.0009 & 0.5617 & 0.9872 \\
R18 & +92.7577 & -0.0541 & +0.0616 & -0.0003 & +0.0007 & & 0.2939 & 0.9796 \\
PDI & +7.3807 & +0.0541 & -0.0416 & +0.0002 & -0.0007 & & 0.3045 & 0.9498 \\
xylan content & +2.5255 & +0.0185 & -0.0312 & +0.0001 & -0.0002 & +0.0001 & 0.0757 & 0.9875 \\
crystallinity index & +54.1866 & -0.0722 & +0.0579 & +0.0015 & & -0.0012 & 0.9715 & 0.9282 \\
cellulose II content & +8.8545 & +0.6078 & -0.5177 & -0.0130 & & +0.0099 & 7.98 & 0.9256 \\
yield & +100.1077 & +0.3114 & -0.1907 & +0.0016 & -0.0043 & & 0.9180 & 0.9723 \\
\hline
\end{tabular}

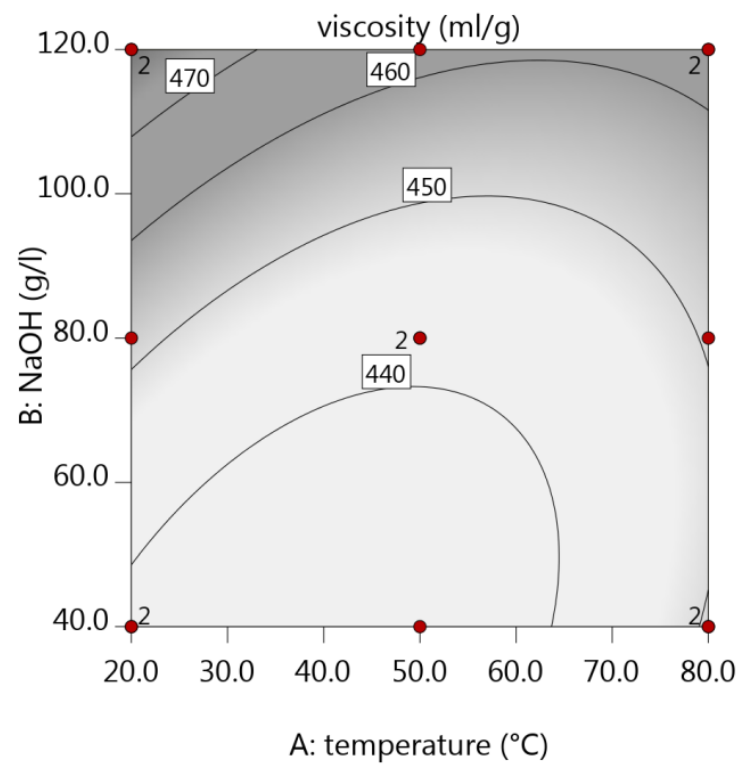

Figure A1. Response surface of pulp viscosity in correlation with temperature and $\mathrm{NaOH}$ concentration.

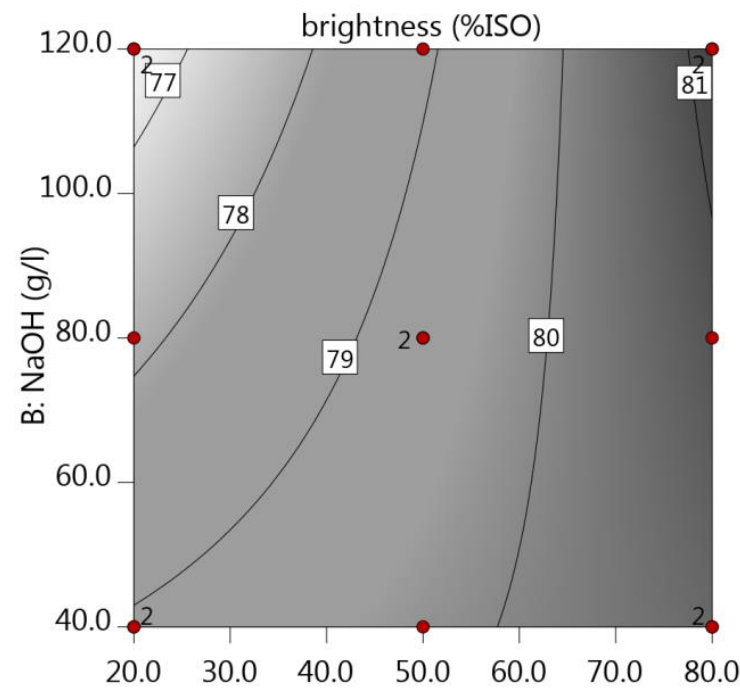

A: temperature $\left({ }^{\circ} \mathrm{C}\right)$

Figure A2. Response surface of brightness in correlation with temperature and $\mathrm{NaOH}$ concentration. 


\section{References}

1. Shen, L.; Worrell, E.; Patel, M.K. Environmental impact assessment of man-made cellulose fibres. Resour. Conserv. Recycl. 2010, 55, 260-274. [CrossRef]

2. Shen, L.; Worrell, E.; Patel, M.K. Comparing life cycle energy and GHG emissions of bio-based PET, recycled PET, PLA, and man-made cellulosics. Biofuel Bioprod. Bior. 2012, 6, 625-639. [CrossRef]

3. Kumar, H.; Christopher, L.P. Recent trends and developments in dissolving pulp production and application. Cellulose 2017, 24, 2347-2365. [CrossRef]

4. Li, H.; Legere, S.; He, Z.; Zhang, H.; Li, J.; Yang, B.; Zhang, S.; Zhang, L.; Zheng, L.; Ni, Y. Methods to increase the reactivity of dissolving pulp in the viscose rayon production process: A review. Cellulose 2018, 25, 3733-3753. [CrossRef]

5. Schlesinger, R.; Röder, T.; Götzinger, G.; Sixta, H.; Harasek, M.; Friedl, A. Influence of hemicellulose aggregate and gel layer formation on flux and retention during nanofiltration of alkaline solutions. Desalination 2005, 175, 121-134. [CrossRef]

6. Schild, G.; Sixta, H. Sulfur-free dissolving pulps and their application for viscose and lyocell. Cellulose 2011, 18, 1113-1128. [CrossRef]

7. Sixta, H. Pulp Purification. In Handbook of Pulp; Sixta, H., Ed.; Wiley-VCH: Weinheim, Germany, 2006; pp. 933-966.

8. Lai, Y.Z. Chemical Degradation. In Wood and Cellulose Chemistry; Hon, D.N.-S., Shiraishi, N., Eds.; Marcel Dekker Inc.: New York, NY, USA, 2001; pp. 443-512.

9. Li, J.; Zhang, H.; Duan, C.; Liu, Y.; Ni, Y. Enhancing hemicelluloses removal from a softwood sulfite pulp. Bioresour. Technol. 2015, 192, 11-16. [CrossRef] [PubMed]

10. Wennerström, M.; Bylund, S. Method for Controlling Viscosity in Dissolving Pulps. WO2017105322, 13 December 2017.

11. Garrood, B.F.; Becker, E.S.; Sen, B. Pretreatment of Sulfite Pulp Before Bleaching with Oxygen Containing Chemicals. CA19942121969, 22 April 1994.

12. Christov, L.P.; Prior, B.A. Xylan removal from dissolving pulp using enzymes of Aureobasidium pullulans. Biotechnol. Lett. 1993, 15, 1269-1274. [CrossRef]

13. Gübitz, G.M.; Lischnig, T.; Stebbing, D.; Saddler, J.N. Enzymatic removal of hemicellulose from dissolving pulps. Biotechnol. Lett. 1997, 19, 491. [CrossRef]

14. Hutterer, C. Enzymatic pulp upgrade for producing high-value cellulose out of a Kraft paper pulp. Enzyme Microb. Technol. 2017, 102, 67-73. [CrossRef] [PubMed]

15. Quintana, E.; Valls, C.; Vidal, T.; Roncero, M.B. Comparative evaluation of the action of two different endoglucanases. Part I: On a fully bleached, commercial acid sulfite dissolving pulp. Cellulose 2015, 22, 2067-2079. [CrossRef]

16. Österreichisches Normungsinstitut. ÖNORM EN 1484 Wasseranalytik-Anleitung zur Bestimmung des Gesamten Organischen Kohlenstoffs (TOC) und des Gelösten Organischen Kohlenstoffs (DOC); Österreichisches Normungsinstitut: Vienna, Austria, 1997.

17. TAPPI. T236 cm-85 Kappa Number of Pulp; TAPPI: Atlanta, GA, USA, 1993.

18. Scandinavian Pulp, Paper and Board Testing Committee. SCAN-CM 15:99 Viscosity in Cupriethylendiamine Solution; Scandinavian Pulp, Paper and Board Testing Committee: Stockholm, Sweden, 1999.

19. ISO. Board and Pulps-Measurement of Diffuse Blue Reflectance Factor; ISO 2470-1 Paper; ISO: Geneva, Switzerland, 2009.

20. Deutsches Institut für Normung, e.V. In DIN 54355 Bestimmung der Beständigkeit von Zellstoff Gegen Natronlauge (Alkaliresistenz); Deutsches Institut für Normung e.V.: Berlin, Germany, 1977.

21. Röder, T.; Moosbauer, J.; Fasching, M.; Bohn, A.; Fink, H.-P.; Baldinger, T.; Sixta, H. Crystallinity Determination of Native Cellulose-Comparison of Analytical Methods. Lenzing. Ber. 2006, 86, 85-89.

22. Wright, P.J.; Wallis, A.F.A. Rapid determination of carbohydrates in hardwoods by high performance anion exchange chromatography. Holzforschung 1996, 50, 518-524. [CrossRef]

23. Schelosky, N.; Röder, T.; Baldinger, T.; Milacher, W.; Morgenstern, B.; Sixta, H. Molecular mass distribution of cellulosic products by size exclusion chromatography in DMAc/LiCl. Das Pap. 1999, 12, 728-738.

24. Huepfl, J.; Zauner, J. Prüfung von Chemiefaserzellstoffen an einer Viskose-Kleinstanlage. Das Pap. 1966, 20, 125-132. 
25. Treiber, E.; Rehnstroem, J.; Ameen, C.; Kolos, F. A small-scale laboratory viscose plant for testing rayon grade pulps. Das Pap. 1962, 16, 85-94.

26. Sixta, H. Pulp Properties and Application. In Handbook of Pulp; Sixta, H., Ed.; Wiley-VCH: Weinheim, Germany, 2006; pp. 1009-1068.

27. Rydholm, S.A. Preparation of Unbleached Pulp. In Pulping Processes; Robert E. Krieger Publishing: Malabar, FL, USA, 1965; pp. 255-835.

28. Wayman, M.; Sherk, D.L. Caustic Extraction of Refined Sulphite Pulp. Tappi 1956, 39, 786-790.

29. Saito, G.-I. The behaviour of cellulose in solutions of alkalies. I. Cross-sectional swelling of fibers of different celluloses in sodium hydroxide solutions at different temperatures. Kolloid-Beihefte 1939, 49, 367-387.

30. Brogdon, B.N. Caustic Extraction in Elemental Chlorine-free Bleaching Sequences for Soft-wood Kraft Pulps: A Fundamental Review and Analysis. In Proceedings of the Engineering, Pulping and Environmental Conference, Portland, OR, USA, 24-27 August 2008; TAPPI Press: Peachtree Corners, GA, USA, 2008.

31. Patt, R.; Kockmann, C.; Kordsachia, O.; Geisenheiner, A. Pulping of Beech Wood Using Different Acid and Alkaline Pulping Processes-A Comparison. Das Pap. 2004, 1, 41-46.

32. Fengel, D.; Wegener, G. Reactions in Acidic Medium. In Wood-Chemistry, Ultrastructure, Reactions; Walter de Gruyter \& Co.: Berlin, Germany, 1989; pp. 268-295.

33. Götze, K. Die Technologie des Viskoseverfahrens. In Chemiefasern nach dem Viskoseverfahren; Springer: Berlin/Heidelberg, Germany, 1967; pp. 779-991.

34. Nascimento Marcos, V.; Manrich, A.; Tardioli Waldir, P.; de Campos Giordano, R.; Jackson de Moraes Rocha, G.; de Lima Camargo Giordano, R. Alkaline pretreatment for practicable production of ethanol and xylooligosaccharides. Bioethanol 2016, 2, 112-125. [CrossRef]

35. Lin, S.H.; Chou, L.M.; Chien, Y.W.; Chang, J.S.; Lin, C.I. Prebiotic Effects of Xylooligosaccharides on the Improvement of Microbiota Balance in Human Subjects. Gastroent. Res. Pract. 2016, 2016, 1-6. [CrossRef] [PubMed]

(C) 2019 by the authors. Licensee MDPI, Basel, Switzerland. This article is an open access article distributed under the terms and conditions of the Creative Commons Attribution (CC BY) license (http:/ / creativecommons.org/licenses/by/4.0/). 